\title{
Enhancing the Production of Polyhydroxyalkanoate Biopolymer by Azohydromonas Australica Using a Simple Empty and Fill Bioreactor Cultivation Strategy
}

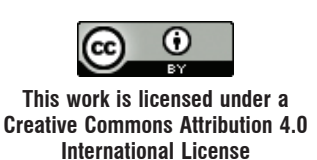

International License

\author{
G. Gahlawat ${ }^{\mathrm{a}, \mathrm{b}}$ and A. K. Srivastava $\mathrm{a}^{\mathrm{b}, *}$ \\ a Department of Microbiology, Panjab University, \\ Sector - 25, Chandigarh - 160014, India \\ bDepartment of Biochemical Engineering and Biotechnology, \\ Indian Institute of Technology Delhi, Hauz Khas, \\ New Delhi - 110016, India
}

doi: 10.15255/CABEQ.2017.1148

Original scientific paper

Received: April 23, 2017

Accepted: November 11, 2017

\begin{abstract}
Polyhydroxyalkanoates (PHAs) are biodegradable polymers which are considered as an effective alternative for conventional plastics due to their mechanical properties similar to the latter. However, widespread use of these polymers is still hampered due to their high cost of production. This shortcoming could partly be resolved by obtaining high yields and productivity. In the present study, a drain-and-fill strategy of repeated-batch cultivation was adopted for the enhanced production of polyhydroxybutyrate PHB using Azohydromonas australica. In this strategy, $20 \%(\mathrm{v} / \mathrm{v})$ of the culture broth was removed from the reactor and supplemented with an equal volume of fresh medium. This strategy demonstrated a 3.3 fold and 1.8 fold increase in PHB concentration and productivity, respectively, as compared to batch cultivation. Repeated cultivation had also the benefit of avoiding non-productive time required for cleaning, refilling and sterilization of bioreactor during batch, thereby increasing the overall volumetric productivity and industrial importance of the process.
\end{abstract}

Key words:

polyhydroxyalkanoates, biodegradation, Azohydromonas, repeated-batch, productivity

\section{Introduction}

Over the past years, synthetic plastics, such as polyethylene and polypropylene, have continuously been used in several industrial and commercial applications due to their low cost and excellent properties of durability, resistance and good processability $^{1}$. However, these synthetic plastics are extremely persistent in nature and accumulate in the environment, thereby leading to a serious problem of solid waste management. The use of petroleum-based plastics in packaging and other products has created a problem worldwide because of their non-biodegradable nature and sustained availability of limited global petroleum reserves ${ }^{2}$. The biotechnological production of polyhydroxyalkanoates (PHAs) polymers from renewable resources provides a sustainable alternative to petroleum-derived plastics, and also reduces the dependency on rapidly disappearing fossils fuels. PHAs are biodegradable, non-toxic, and their material properties are similar to petrochemically derived plastics ${ }^{3,4}$. Moreover, PHAs can

"Corresponding author: Prof. Ashok K. Srivastava;

Tel: +91-11-26591010; fax: +91-11-26582282,

E-mail:ashokiitd@gmail.com; ashokks@dbeb.iitd.ac.in be produced from renewable feedstock under normal temperature and pressure conditions, unlike the petrochemically derived plastics that are produced by fractional distillation of depleting fossil fuels with the consumption of a vast amount of energy. They have various potential applications particularly in newly emerging areas, such as tissue engineering, targeted drug delivery, and agricultural fields ${ }^{5,6}$.

In spite of all these advantages of PHAs compared to synthetic plastics, the main bottleneck in the commercialization of PHAs is their significantly high cost of production ${ }^{7}$. It has been indicated that the production cost of any fermentation process can be substantially reduced by utilization of inexpensive substrates and the optimization of fermentation process $^{8-10}$. One of the major objectives during fermentation process optimization is to enhance the product yield and productivity while minimizing the substrate limitation and inhibition problem during the cultivation. Fed-batch fermentation strategy has been used by various researchers with an aim to maximize polyhydroxybutyrate PHB concentration and avoid substrate inhibitions and/or limitations at the same time ${ }^{11-14}$. However, the success of such fed-batch strategy(ies) requires development of an on-line monitoring and control system 
for estimation of residual substrates and/or fresh nutrients addition. Several investigators have adopted single and multistage continuous cultivation approaches, and cell retention techniques to enhance the PHB productivity and concentrations ${ }^{15,16}$. However, these techniques have high risk of microbial contamination and cell growth on the reactor walls resulting in substantial financial loss. A simple and well-known cultivation strategy, which could be beneficial in enhancing PHB production is repeatedbatch cultivation. The empty-and-fill protocol of repeated-batch cultivation could be extended for any number of cycles as compared to fed-batch strategies wherein productivity is limited by the working volume of bioreactor ${ }^{17}$.

Repeated-batch cultivation helps in increasing the longevity of the otherwise decaying culture in the bioreactor by supplementing fresh substrates during each feed cycle. The main advantages of repeated-batch cultivation are its ease of operation, enhancement of culture stability towards contamination, minimization of pre-culture effects and maintenance of organism at high growth rates. Khanna and Srivastava (2005) investigated the use of one such cultivation strategy for the PHB production by $R$. eutropha and demonstrated significant improvement in process productivity after $67 \mathrm{~h}^{17}$. Because of its ease of operation and economical feasibility, this strategy has also been used for the production of other metabolites, such as xylitol from Candida guilliermondii ${ }^{18}$ and butyric acid from Clostridium tyrobutyricum ${ }^{19}$. In another study, Qi et al. (2015) demonstrated that the repeated cycle mode could enhance the yield and volumetric productivity of D-arabitol fermentation process by Zygosaccharomyces rouxii ${ }^{20}$. Volumetric productivity of D-arabitol was enhanced from $0.86 \mathrm{~g} \mathrm{~L}^{-1} \mathrm{~h}^{-1}$ in batch to $1.143 \mathrm{~g} \mathrm{~L}^{-1} \mathrm{~h}^{-1}$ in repeated cycle mode, which was a total increment of $32.9 \%$ after $72 \mathrm{~h}$ of fermentation. Thus, the performance of cyclic batches in terms of yield and productivity was better than that of batch mode.

In the present study, the empty-and-fill strategy of cultivation was utilized for PHB production in 7-L bioreactor, and a comparison with the batch mode fermentation was done to evaluate the performance of repeated-batch in terms of PHB accumulation and productivity. On the basis of encouraging results, it was concluded that this strategy can be further scaled up to pilot level for testing the techno-economic feasibility of the process. For PHB production, Azohydromonas australica strain was employed because it can accumulate PHB up to $80 \%$ of cell dry mass (CDM) particularly in growth associated mode, and can grow easily on inexpensive substrate, sucrose ${ }^{21,22}$. The developed process showed the amalgamation of high yielding strain, cheap substrate, and a simple time-saving cultivation strategy to increase the production of PHB.

\section{Experimental}

\section{Microorganism}

Azohydromonas australica DSM 1124 (earlier known as Alcaligenes latus) was obtained from German Collection of Microorganisms and Cell Cultures (DSMZ, Germany). The strain was maintained on nutrient agar slants and stored at $4{ }^{\circ} \mathrm{C}$.

\section{Growth medium and inoculum development}

The growth of microorganism was carried out in a statistically optimized medium consisting of: $25 \mathrm{~g} \mathrm{~L}^{-1}$ sucrose, $2.8 \mathrm{~g} \mathrm{~L}^{-1}\left(\mathrm{NH}_{4}\right)_{2} \mathrm{SO}_{4}, 3.25 \mathrm{~g} \mathrm{~L}^{-1}$ $\mathrm{KH}_{2} \mathrm{PO}_{4}, 3.25 \mathrm{~g} \mathrm{~L}^{-1} \mathrm{Na}_{2} \mathrm{HPO}_{4}, 0.2 \mathrm{~g} \mathrm{~L}^{-1} \mathrm{MgSO}_{4}$, $1.5 \mathrm{~mL} \mathrm{~L}^{-1}$ trace element solution ${ }^{9}$. Phosphates solution was autoclaved separately to avoid precipitation during medium preparation, and trace element solution was filter sterilized using $0.22 \mu \mathrm{m}$ pore size filter (Millipore, Ireland). For inoculum preparation, $50 \mathrm{~mL}$ sterile medium was taken in $250 \mathrm{~mL}$ flask wherein the $\mathrm{pH}$ of the medium was adjusted at 7.0 using $2 \mathrm{~N} \mathrm{NaOH} / \mathrm{HCl}$. The shake flasks were inoculated aseptically and then kept in the rotating shaker at $200 \mathrm{rpm}$ and $33{ }^{\circ} \mathrm{C}$ for $48 \mathrm{~h}$ for inoculum preparation. Before the operation of the bioreactor, the exponentially growing culture $(5 \% \mathrm{v} / \mathrm{v})$ was further inoculated into 1-L flasks containing $200 \mathrm{~mL}$ optimized media and allowed to grow for $24 \mathrm{~h}$ until the log phase was achieved. The culture so obtained was then used as the inoculum.

\section{Fermentation in a 7-L bioreactor}

The batch and repeated-batch cultivation of the culture A. australica was carried out in a 7-L bioreactor (Applikon Dependable Instruments, The Netherlands) containing 4-L optimized nutrient medium (Fig. 1). The bioreactor was equipped with two conventional flat blade turbine impellers and three baffles. Air sparging was done from the bottom of the reactor using an L-shaped stainless steel sparger. The temperature was controlled at $33{ }^{\circ} \mathrm{C}$ by circulating water from the chilled water unit (Julabo FP50, Germany). Culture $\mathrm{pH}$ was controlled at 7.0 by automatic addition of $2 \mathrm{~N} \mathrm{NaOH} / 2 \mathrm{~N} \mathrm{HCl}$. The dissolved oxygen concentration in the bioreactor was measured using an in situ Applisens dissolved oxygen probe (Applikon Dependable Instruments, The Netherlands). Samples were analyzed at regular intervals of $3 \mathrm{~h}$. Repeated-batch cultivation was initiated as batch using statistically optimized media. When sucrose concentration inside the bioreactor had depleted to a limiting concentration (below 8 $\mathrm{g} \mathrm{L}^{-1}$ ), the batch cultivation was converted to nutrient feed cycle mode wherein $20 \%(\mathrm{v} / \mathrm{v})$ culture broth was removed from the reactor and refilled 

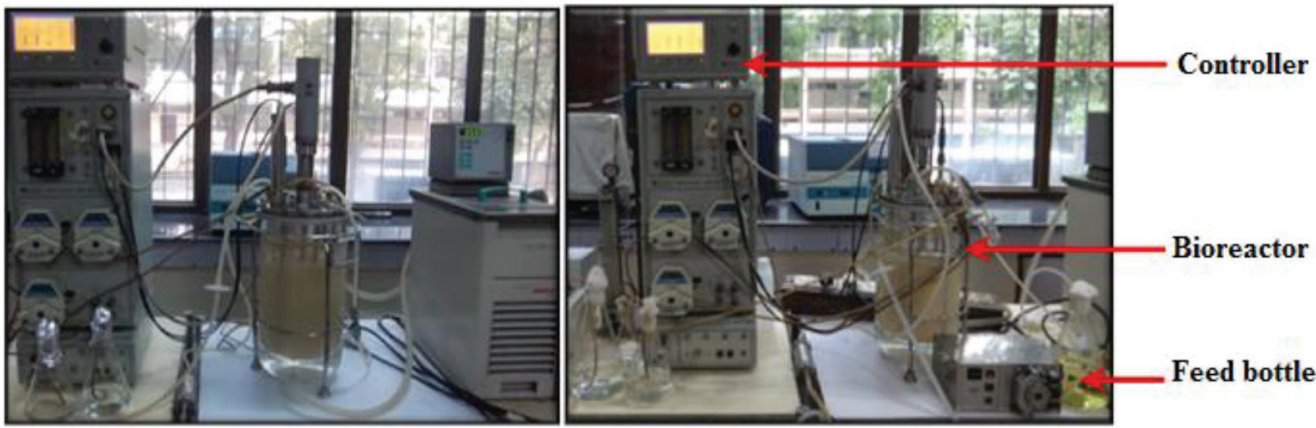

Fig. 1 - Complete experimental set up of (a) batch cultivation (b) repeated-batch cultivation in the 7-L bioreactor (Applikon Dependable Instrument, The Netherlands)

with an equal volume of fresh medium (having the same recipe as used in start up of batch cultivation). Three cycles of repeated-batch cultivation were executed in a similar manner.

\section{Analytical methods}

Optical density of culture broth was measured at $600 \mathrm{~nm}$ against a medium blank using spectrophotometer (OPTIZEN model 3220UV, Mecasys, Korea). Total biomass was measured from a plot of $\mathrm{OD}_{600 \mathrm{~nm}}$ vs. CDM ( $\left.\mathrm{g} \mathrm{L}^{-1}\right)$ correlation. The correlation factor was calculated from slope of the plot and $1 \mathrm{~g} \mathrm{~L}^{-1} \mathrm{CDM}$ correlated to 2.476 OD. PHB content inside the cells was analyzed by gas chromatography (GC 2010 Shimadzu Co., Japan), and benzoic acid was used as an internal standard ${ }^{23}$. Residual sucrose concentration was determined by the Di-Nitro Salicylic acid (DNS) method ${ }^{24}$. The total nitrogen assay was done by measuring the residual ammonia in cell-free supernatant using Kjeldahl method ${ }^{25}$.

\section{PHB determination by gas chromatography}

For determination of PHB, $40 \mathrm{mg}$ of dried cells were was dissolved by heating in $10 \mathrm{~mL}$ of 1,2 -dichloroethane (DCE). After cooling to room temperature, $2 \mathrm{~mL}$ of DCE, $2 \mathrm{~mL}$ of acidified propanol (1:-4:: hydrochloric acid:-propanol) and $200 \mu \mathrm{L}$ of benzoic acid (40 $\mathrm{g} \mathrm{L}^{-1}$ benzoic acid prepared in propanol) was then added. The bottles were sealed with rubber seals/aluminium caps and crimped. The bottles were then kept in an oven at $100{ }^{\circ} \mathrm{C}$ for $2 \mathrm{~h}$. PHB was thus depolymerized and transesterified into propyl ester of hydroxybutyric acid (HBA) using acidified propanol. After cooling to room temperature, $4 \mathrm{~mL}$ of distilled water was then added and the mixture was shaken for 20-30 seconds. The heavier phase (DCE-propanol) was injected into the gas chromatograph column. The carrier gas (nitrogen) flow rate and the initial oven temperature were $1.5 \mathrm{~mL} \mathrm{~min}^{-1}$ and $110^{\circ} \mathrm{C}$, respectively. The injection port temperature was $160{ }^{\circ} \mathrm{C}$ and the detector (Flame-Ionization) temperature was $170{ }^{\circ} \mathrm{C}$. The areas of ester of HBA and ester of benzoic acid obtained from the GC graph were used to calculate the amount of PHB produced ${ }^{23}$.

\section{Results and discussion}

\section{Batch cultivation}

Fig. 2a demonstrates the time course of batch cultivation of $A$. australica for PHB production in the 7-L bioreactor. During batch cultivation, the culture exhibited an initial lag phase of around $3 \mathrm{~h}$, after which it started to grow exponentially. The synthesis of PHB also started simultaneously after lag phase $(3 \mathrm{~h})$ because of growth-associated PHB accumulation in $A$. australica. Batch fermentation featured accumulation of $8.71 \mathrm{~g} \mathrm{~L}^{-1} \mathrm{CDM}$ and $6.24 \mathrm{~g} \mathrm{~L}^{-1}$ PHB concentration in $36 \mathrm{~h}$ of cultivation period, thereby resulting in a maximum PHB productivity of $0.17 \mathrm{~g} \mathrm{~L}^{-1} \mathrm{~h}^{-1}$. The culture reached stationary phase after $36 \mathrm{~h}$. It was important to establish the batch growth and product kinetics in the 7-L bioreactor under controlled environmental conditions as this would yield the basic kinetic parameters that could then be compared with repeatedbatch for optimal product formation. Previously, Zafar et al. (2012) investigated the use of A. lata MTCC 2311 for batch PHB production using genetic algorithm approach based on artificial neural network $^{26}$. A maximum CDM concentration of 10.56 $\mathrm{g} \mathrm{L}^{-1}$ and PHB concentration of $5.1 \mathrm{~g} \mathrm{~L}^{-1}$ was obtained using $35.2 \mathrm{~g} \mathrm{~L}^{-1}$ sucrose with an overall PHB content of $48 \%$ of CDM. Thus, the overall PHB content and productivity were very low as compared to the present study.

\section{Repeated cultivation strategy}

On other hand, repeated-batch cultivation is a simple, well-known strategy, which offers several operational advantages over batch and conventional fed-batch cultivation to obtain significantly high cell growth, PHB concentration, and productivity. 


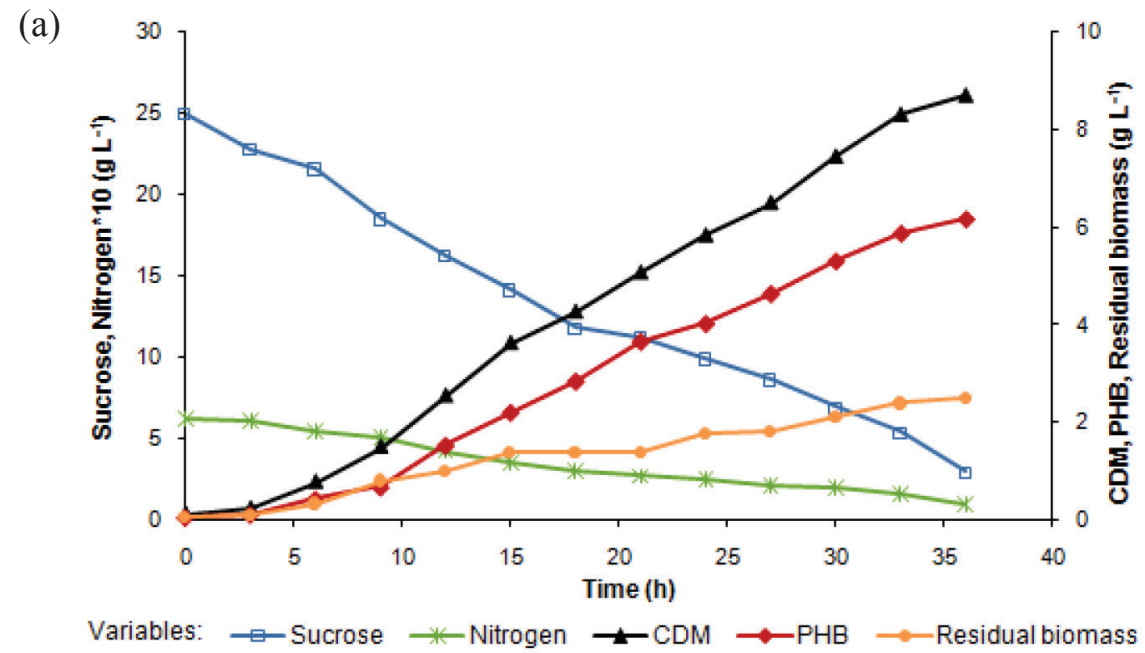

(b)

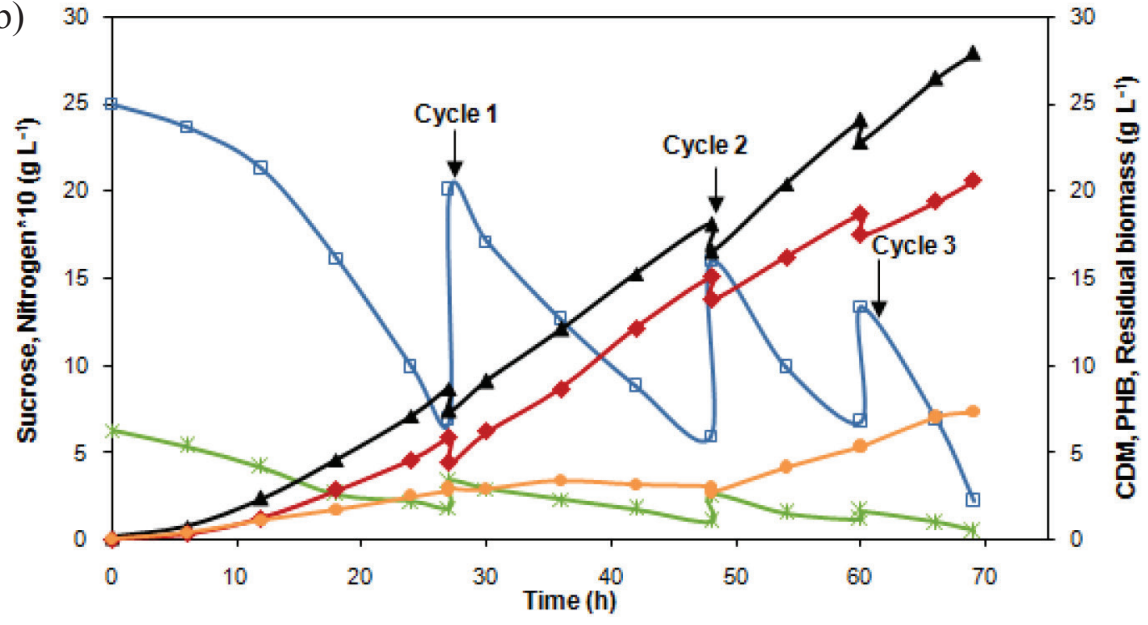

Variables: $\square$ Sucrose $\because$ Nitrogen $\rightarrow$ CDM $\rightarrow$ PHB $\multimap-$ Residual biomass

Fig. 2 - (a) Batch kinetics of cell growth, nutrient consumption, and PHB production for A. australica in the 7-L bioreactor (b) repeated-batch cultivation kinetics of A. australica for PHB production. Three cycles of repeated-batch were performed at $27 \mathrm{~h}, 48 \mathrm{~h}$ and $60 \mathrm{~h}$

The time course of repeated-batch cultivation of $A$. australica involving three cycles of culture withdrawal and fresh nutrients addition is depicted in Fig. 2b. During repeated-batch cultivation, $20 \%$ $(\mathrm{v} / \mathrm{v})$ culture broth was removed from the reactor and supplemented with an equal volume of fresh medium at each cycle, which was initiated at $27 \mathrm{~h}$, $48 \mathrm{~h}$ and $60 \mathrm{~h}$ when the residual sucrose concentration in the fermentation medium had dropped below $8 \mathrm{~g} \mathrm{~L}^{-1}$. The time of broth removal and subsequent refilling of fresh medium (having the same recipe as used in batch cultivation) was calculated based on off-line residual sucrose analysis by the DNS method.

The first cycle of fresh nutrients addition was attempted at $27 \mathrm{~h}$ because of low availability of substrate concentration (below $8 \mathrm{~g} \mathrm{~L}^{-1}$ ) inside the bioreactor at that time. Upon nutrients addition, a slight decrease in cell concentration was observed primarily because of dilution of the culture broth by the fresh medium addition; however, it increased again after a certain time due to heavy inoculum ratio $(80 \% \mathrm{v} / \mathrm{v})$ available inside the bioreactor. This cycle was continued until the sucrose concentration in the fermentation medium had again dropped below $8 \mathrm{~g} \mathrm{~L}^{-1}$ (till $48 \mathrm{~h}$ ). At $48 \mathrm{~h}$, a second cycle of broth removal and subsequent refilling with fresh medium was attempted. It was observed that the culture continuously maintained its metabolic activities and continued to produce PHB even after 2 cycles of empty-and-fill protocol strategy. At the end of the second cycle (at $60 \mathrm{~h}$ ), a significantly high $\mathrm{CDM}$ and PHB concentration of $24.95 \mathrm{~g} \mathrm{~L}^{-1}$ and $18.79 \mathrm{~g} \mathrm{~L}^{-1}$ was obtained. The empty-and-fill strategy of repeated-batch helped in maintaining high growth and substrate consumption rates during cy- 
Table 1 -Dynamic rates of A. australica fermentation during empty and fill cultivation strategy

\begin{tabular}{c|c|c|c|c}
\hline Time $(\mathrm{h})$ & $\mathrm{d} X / \mathrm{d} t$ & $\mathrm{~d} S_{\mathbf{1}} / \mathrm{d} t$ & $\mathrm{~d} S_{\mathbf{2}} / \mathrm{d} t$ & $\mathrm{~d} P / \mathrm{d} t$ \\
\hline 12 & 0.3924 & -0.3931 & -0.00787 & 0.1611 \\
24 & 0.2138 & -0.2781 & -0.00709 & 0.1782 \\
27 & 0.2832 & -1.5452 & -0.00887 & 0.0909 \\
36 & 0.5212 & -0.7933 & -0.00631 & 0.2381 \\
48 & 0.4305 & -1.4485 & -0.00686 & 0.1858 \\
60 & 0.2344 & -0.9174 & -0.00576 & 0.1040 \\
\hline
\end{tabular}

$\mathrm{d} Y / \mathrm{d} t-$ dynamic rates; where $Y$ represents process variables: $X$ - CDM, $S_{1}$-sucrose, $S_{2}$-nitrogen, $P$-PHB

cles 1 and 2 , respectively (as shown in Table 1). Table 1 demonstrates the dynamic rates of $\operatorname{CDM}(X)$ accumulation, substrates: sucrose $\left(S_{1}\right)$ and nitrogen $\left(S_{2}\right)$ consumptions, and product $(P)$ formation during different phases of cultivation. A significant drop in CDM synthesis, substrates consumption, and PHB production rates was obtained towards the end of batch cycle $(24 \mathrm{~h})$. Initiation of fresh nutrients feeding at $27 \mathrm{~h}$ and $48 \mathrm{~h}$ promoted further growth and PHB production by $A$. australica. This was clearly noticeable by increase in sucrose consumption rates, resulting in high cell concentration and PHB formation rates.

Based on these motivating results obtained in earlier cycles, it was decided to attempt yet another cycle (third cycle) to assess any further increase in PHB production upon fresh medium addition. At $60 \mathrm{~h}$, a third cycle of repeated-batch was initiated in a similar manner as mentioned previously for the two cycles. It was concluded that the increase in $\mathrm{CDM}$ and PHB concentration during this cycle was not very significant, unlike in the previous cycles, and the fermentation stopped at $69 \mathrm{~h}$. This cyclic strategy yielded an overall PHB productivity of $0.29 \mathrm{~g} \mathrm{~L}^{-1} \mathrm{~h}^{-1}$. During repeated-batch operation, a final CDM and PHB concentration of $27.89 \mathrm{~g} \mathrm{~L}^{-1}$ and $20.55 \mathrm{~g} \mathrm{~L}^{-1}$, respectively, was obtained in $69 \mathrm{~h}$. On the other hand, three cycles of culture removal and fresh nutrients addition at $27 \mathrm{~h}, 48 \mathrm{~h}$ and $60 \mathrm{~h}$ resulted in 1.8-fold and 3.3-fold increase in PHB productivity and concentrations, respectively, as compared to batch cultivation $\left(8.71 \mathrm{~g} \mathrm{~L}^{-1} \mathrm{CDM}\right.$ and $6.24 \mathrm{~g} \mathrm{~L}^{-1}$ PHB) (Fig. 2a). Batch cultivations are usually associated with the limitation of essential nutrients (sucrose and nitrogen both) during the course of fermentation, particularly at the times when cells are in the exponentially growing stage. This may affect the growth of the culture or may lead to complete killing of the cells. Besides, batch experiments cannot be initiated with a very high concentration of substrates in the feed medium as it might lead to typical substrate inhibition phenomenon. In such a case, repeated-batch cultivation could be a better solution which ensures slow feeding of substrate and adequate nutrient availability during the entire cultivation, while avoiding any inhibition problem arising from over-feeding of the substrates. Table 2 shows the growth and product kinetic parameters of $A$. australica obtained during repeated-batch. A maximum PHB yield $\left(Y_{P S S}\right)$ and productivity of $0.39 \mathrm{~g} \mathrm{~g}^{-1}$ and $0.31 \mathrm{~g} \mathrm{~L}^{-1} \mathrm{~h}^{-1}$, respectively, were obtained at $48 \mathrm{~h}$. At the end of fermentation, the CDM yield $\left(Y_{X / S}\right)$ and PHB yield $\left(Y_{P / S}\right)$ on sucrose were observed to be $0.39 \mathrm{~g} \mathrm{~g} \mathrm{~g}^{-1}$ and $0.30 \mathrm{~g} \mathrm{PHB} \mathrm{g}^{-1}$ sucrose, respectively, and total PHB content was $74 \%$ of CDM.

\section{Comparative account with literature}

It was concluded that only a slight extension of normal batch cultivation already continuing in the bioreactor could lead to improvement in PHB concentration and productivity in minimum time with less pre-culture preparation. Moreover, by conversion of batch cultivation into cyclic mode (emptyand-fill protocol), the non-productive time of cleaning, filling and sterilization of the bioreactor for the initiation of fresh batch cultivation could be completely eliminated. To the best of our knowledge, to date, there has been only one report on repeated-batch fermentation of PHB production by $A$. australica $^{27}$ (Table 3). However, the PHB concentration and productivity obtained in their study were very low even after four cycles of repeated cultiva-

Table 2 - Growth and product kinetic parameters of A. australica during repeated-batch fermentation

\begin{tabular}{c|c|c|c|c|c|c|c|c|c}
\hline $\begin{array}{c}\text { Batch } \\
\text { cycle }\end{array}$ & $\begin{array}{c}\text { Time } \\
(\mathrm{h})\end{array}$ & $\begin{array}{c}\mathrm{CDM} \\
\left(\mathrm{g} \mathrm{L}^{-1}\right)\end{array}$ & $\begin{array}{c}\text { PHB } \\
\left(\mathrm{g} \mathrm{L}^{-1}\right)\end{array}$ & $\begin{array}{c}\text { Residual } \\
\text { sucrose } \\
\left(\mathrm{g} \mathrm{L}^{-1}\right)\end{array}$ & $\begin{array}{c}Q_{P}^{*} \\
\left(\mathrm{~g} \mathrm{~L}^{-1} \mathrm{~h}^{-1}\right)\end{array}$ & $\begin{array}{c}\text { PHA }_{\mathrm{C}}^{*} \\
(\%)\end{array}$ & $\begin{array}{c}Y_{P / S}^{*} \\
\left(\mathrm{~g} \mathrm{~g}^{-1}\right)\end{array}$ & $\begin{array}{c}Y_{X / S}^{*} \\
\left(\mathrm{~g} \mathrm{~g}^{-1}\right)\end{array}$ & $\begin{array}{c}Y_{X / N}^{*} \\
\left(\mathrm{~g} \mathrm{~g}^{-1}\right)\end{array}$ \\
\hline 1 & 27 & 8.52 & 5.84 & 6.95 & 0.20 & 68 & 0.32 & 0.47 & 4.30 \\
2 & 48 & 18.43 & 15.10 & 5.90 & 0.31 & 82 & 0.59 & 0.69 & 9.52 \\
3 & 60 & 24.90 & 18.79 & 6.82 & 0.29 & 76 & 0.40 & 0.71 & 10.26 \\
4 & 69 & 27.89 & 20.55 & 2.82 & 0.30 & 73 & 0.16 & 0.28 & 5.98 \\
\hline
\end{tabular}

* $Q_{P}-$ PHB productivity; $Y_{P S}-$ PHB yield on sucrose; $Y_{X / S}-$ CDM yield on sucrose; PHA - PHB content; $Y_{X N}-$ CDM yield on ammonium sulfate (nitrogen source) 
Table 3 -Comparison of present repeated batch strategy with literature reports for PHB production using Azohydromonas australica or similar strains

\begin{tabular}{|c|c|c|c|c|}
\hline $\begin{array}{c}\text { Micro- } \\
\text { organism }\end{array}$ & $\begin{array}{c}\text { PHB } \\
\text { concentration } \\
\left(\mathrm{g} \mathrm{L}^{-1}\right)\end{array}$ & $\begin{array}{c}\text { PHB } \\
\text { content } \\
(\% \mathrm{CDM})\end{array}$ & $\begin{array}{c}Q_{P}^{\#} \\
\left(\mathrm{~g} \mathrm{~L}^{-1} \mathrm{~h}^{-1}\right)\end{array}$ & References \\
\hline $\begin{array}{l}\text { A. australica* } \\
\text { DSM } 1124\end{array}$ & 22.65 & 76 & 0.59 & 11 \\
\hline $\begin{array}{l}\text { A. latus } * * \\
\text { DSM } 1124\end{array}$ & 3.1 & - & 0.21 & 27 \\
\hline $\begin{array}{l}\text { A. latus } * * \\
\text { DSM } 1123\end{array}$ & 3.6 & 50 & 0.26 & 28 \\
\hline $\begin{array}{l}\text { A. latus }{ }^{* *} \\
\text { DSM } 1123\end{array}$ & 29.64 & 75 & 0.6 & 29 \\
\hline $\begin{array}{l}\text { A. latus } * * \\
\text { DSM } 1123\end{array}$ & 22.8 & 70 & 0.44 & 30 \\
\hline $\begin{array}{l}\text { A. latus }{ }^{* *} \\
\text { DSM } 1123\end{array}$ & 14.53 & 53 & 0.78 & 31 \\
\hline $\begin{array}{l}\text { A. latus } * * \\
\text { ATCC } 29712\end{array}$ & 12.41 & 66 & 0.069 & 32 \\
\hline $\begin{array}{l}\text { A. latus } * * \\
\text { DSM } 1123\end{array}$ & 2.55 & 78 & 0.065 & 33 \\
\hline $\begin{array}{l}\text { A. latus } * * \\
\text { DSM } 1123\end{array}$ & 12.67 & 66 & 0.52 & 34 \\
\hline $\begin{array}{l}\text { A. australica* } \\
\text { DSM } 1124\end{array}$ & 20.55 & 73 & 0.29 & $\begin{array}{l}\text { Present } \\
\text { study }\end{array}$ \\
\hline
\end{tabular}

PHB productivity $\left(\mathrm{g} \mathrm{L}^{-1} \mathrm{~h}^{-1}\right)$; Azohydromonas australica; ** Alcaligenes latus

tion. This report featured the removal of $10 \%(\mathrm{v} / \mathrm{v})$ of the culture broth as the next seed inoculum and subsequent addition into fresh medium. This procedure was repeated for four cycles, CDM and PHB concentrations were increased as compared to the batch fermentation. During repeated-batch process, a maximum PHB concentration and productivity of $3.1 \mathrm{~g} \mathrm{~L}^{-1}$ and $0.21 \mathrm{~g} \mathrm{~L}^{-1} \mathrm{~h}^{-1}$, respectively, were obtained. There was a 2.33 -fold and 1.4-fold increase in PHB productivity and concentrations, respectively, as compared to batch cultivation. None of the earlier reports on repeated-batch cultivation had achieved high PHB concentration and productivity by $A$. australica. Ibrahim and Steinbuchel (2010) had also investigated the use of repeated-batch cultivation with cell recycle for PHB production ${ }^{13}$. Different fermentation strategies were attempted for the cultivation of a new PHB-accumulating thermophilic bacterium, Chelatococcus sp. MW10, with the objective of achieving high biomass growth and PHB productivity. Enhanced PHB production was achieved only with the repeated-batch fermentation or repeated-batch technique (42-L scale). Three cycles of culture withdrawal and subsequent refilling with fresh substrates resulted in a high cell density concentration of $115 \mathrm{~g} \mathrm{~L}^{-1}$, PHB content of $11.8 \%$, and $13.6 \mathrm{~g} \mathrm{~L}^{-1}$ of PHB at the end of the cultivation $(265 \mathrm{~h})$. Table 3 shows the comparison of the present cultivation strategy with other literature reports on PHB production using A. australica and similar strains.

\section{Conclusion}

A simple empty and fill protocol strategy of repeated-batch was followed in the present study for enhancement in PHB concentration and productivity by $A$. australica. Three cycles of culture broth removal and subsequent refilling with fresh medium at $27 \mathrm{~h}, 48 \mathrm{~h}$ and $60 \mathrm{~h}$, resulted in a maximum PHB concentration of $20.55 \mathrm{~g} \mathrm{~L}^{-1}$ with an overall productivity of $0.29 \mathrm{~g} \mathrm{~L}^{-1} \mathrm{~h}^{-1}$. The present work demonstrated 3.3 fold and 1.8 fold increases in PHB concentration and productivity, respectively, over batch cultivation. The developed cultivation strategy can be transferred to large-scale level to check the techno-economic feasibility of the process, which will be the topic of our future investigation.

\section{ACKNOWLEDGEMENT}

The Senior Research Fellowship (SRF) award by Department of Biotechnology (DBT), Govt of India, New Delhi for the execution of project is gratefully acknowledged by one of the authors (Geeta Gahlawat).

\section{References}

1. Akaraonye, E., Keshavarz, T., Roy, I., Production of polyhydroxyalkanoates: The future green materials of choice, J. Chem. Technol. Biotechnol. 85 (2010) 732.

doi: https://doi.org/10.1002/jctb.2392

2. Castilho, L. R., Mitchell, D. A., Freire, D. M., Production of polyhydroxyalkanoates (PHAs) from waste materials and by-products by submerged and solid-state fermentation, Bioresour. Technol. 100 (2009) 5996.

doi: https://doi.org/10.1016/j.biortech.2009.03.088

3. Cavalheiro, J. M., de Almeida, M. C. M., Grandfils, C., Da Fonseca, M., Poly (3-hydroxybutyrate) production by $\mathrm{Cu}$ priavidus necator using waste glycerol, Process Biochem. 44 (2009) 509.

doi: https://doi.org/10.1016/j.procbio.2009.01.008

4. Loo, C. Y., Sudesh, K., Polyhydroxyalkanoates: bio-based microbial plastics and their properties, Malaysian Polym. J. 2 (2007) 31.

5. Chanprateep, S., Current trends in biodegradable polyhydroxyalkanoates, J. Biosci. Bioeng. 110 (2010) 621. doi: https://doi.org/10.1016/j.jbiosc.2010.07.014

6. Philip, S., Keshavarz, T., Roy, I., Polyhydroxyalkanoates: biodegradable polymers with a range of applications, J. Chem. Technol. Biotechnol. 82 (2007) 233. doi: https://doi.org/10.1002/jctb.1667 
7. Divya, G., Archana, T., Manzano, R. A., Polyhydroxy alkanoates - a sustainable alternative to petro-based plastics, J. Pet. Environ. Biotechnol. 4 (2013) 2. doi: https://doi.org/10.4172/2157-7463.1000143

8. El-Sayed, A. A., Abdelhady, H. M., Abdel Hafez, A., Khodair, T. L., Batch production of polyhydroxybutyrate (PHB) by Ralstonia eutropha and Alacaligenes latus using bioreactor different culture strategies, J. Appl. Sci. Res. 5 (2009) 556.

9. Gahlawat, G., Srivastava, A. K., Estimation of fundamental kinetic parameters of polyhydroxybutyrate fermentation process of Azohydromonas australica using statistical approach of media optimization, Appl. Biochem. Biotechnol. 168 (2012) 1051

doi: https://doi.org/10.1007/s12010-012-9840-3

10. Koller, M., Maršálek, L., de Sousa Dias, M. M., Braunegg, $G$., Producing microbial polyhydroxyalkanoate (PHA) biopolyesters in a sustainable manner, New Biotechnol. 37 (2017) 24

doi: https://doi.org/10.1016/j.nbt.2016.05.001

11. Gahlawat, G., Srivastava, A. K., Development of a mathematical model for the growth associated Polyhydroxybutyrate fermentation by Azohydromonas australica and its use for the design of fed-batch cultivation strategies, Bioresour. Technol. 137 (2013) 98. doi: https://doi.org/10.1016/j.biortech.2013.03.023

12. Grothe, E., Chisti, Y., Poly ( $\beta$-hydroxybutyric acid) thermoplastic production by Alacaligenes latus: behavior of fedbatch cultures, Bioprocess Eng. 22 (2000) 441. doi: https://doi.org/10.1007/s004490050757

13. Ibrahim, M. H., Steinbüchel, A., High-cell-density cyclic fed-batch fermentation of a poly (3-hydroxybutyrate)-accumulating thermophile, Chelatococcus sp. strain MW10, Appl. Environ. Microbiol. 76 (2010) 7890. doi: https://doi.org/10.1128/AEM.01488-10

14. Ienczak, J. L., Schmidell, W., de Aragão, G. M. F. High-cell-density culture strategies for polyhydroxyalkanoate production: a review, J. Ind. Microbiol. Biotechnol. 40 (2013) 275. doi: https://doi.org/10.1007/s10295-013-1236-Z

15. Koller, M., Muhr, A., Continuous production mode as a viable process-engineering tool for efficient poly (hydroxyalkanoate) (PHA) bio-production, Chem. Biochem. Eng. Q. 28 (2014) 65.

16. Haas, C., El-Najjar, T., Virgolini, N., Smerilli, M., Neureiter, $M$., High cell-density production of poly (3-hydroxybutyrate) in a membrane bioreactor, New Biotechnol. 37 (2017) 117. doi: https://doi.org/10.1016/j.nbt.2016.06.1461

17. Khanna, S., Srivastava, A. K., Cyclic fed-batch cultivation of Ralstonia eutropha for poly ( $\beta$-hydroxybutyrate) production, Biotechnol. Lett. 27 (2005) 1401. doi: https://doi.org/10.1007/s10529-005-0689-1

18. Cunha, M., Rodrigues, R., Santos, J., Converti, A., da Silva, $S$., Repeated-batch xylitol bioproduction using yeast cells entrapped in polyvinyl alcohol-hydrogel, Curr. Microbiol. 54 (2007) 91. doi: https://doi.org/10.1007/s00284-005-0465-4

19. Huang, J., Dai, H., Yan, R., Wang, P., Enhanced production of butyric acid through immobilization of Clostridium tyrobutyricum in a novel inner disc-shaped matrix bioreactor, Ann. Microbiol. 66 (2015) 121. doi: https://doi.org/10.1007/s13213-015-1088-z

20. Qi, X., Luo, Y., Wang, X., Zhu, J., Lin, J., Zhang, H., Chen, $F$., Sun, $W$., Enhanced d-arabitol production by Zygosaccharomyces rouxii JM-C46: isolation of strains and process of repeated-batch fermentation, J. Ind. Microbiol. Biotechnol. 42 (2015) 807.

doi: https://doi.org/10.1007/s10295-015-1603-Z
21. Gahlawat, G., Sengupta, B., Srivastava, A. K., Enhanced production of poly (3-hydroxybutyrate) in a novel airlift reactor with in situ cell retention using Azohydromonas australica, J. Ind. Microbiol. Biotechnol. 39(9) (2012) 1377. doi: https://doi.org/10.1007/s10295-012-1138-5

22. Gahlawat, G., Srivastava, A. K., Use of NAD (P) H fluorescence measurement for on-line monitoring of metabolic state of Azohydromonas australica in poly (3-hydroxybutyrate) production, Appl. Biochem. Biotechnol. 169(3) (2013) 821 doi: https://doi.org/10.1007/s12010-012-0040-y

23. Riis, $V$., Mai, W., Gas chromatographic determination of poly- $\beta$-hydroxybutyric acid in microbial biomass after hydrochloric acid propanolysis, J. Chrom. A. 445 (1988) 285. doi: https://doi.org/10.1016/S0021-9673(01)84535-0

24. Miller, G. L., Use of dinitrosalicylic acid reagent for determination of reducing sugar, Anal. Chem. 31 (1959) 426. doi: https://doi.org/10.1021/ac60147a030

25. Horwitz, W., Senzel, A., Reynolds, H., Park, D. L., Official methods of analysis of the Association of Official Analytical Chemists, Off. Meth. Anal. Ass. Of. Analy. Chem. (Ed. 12) (1975).

26. Zafar, M., Kumar, S., Kumar, S., Dhiman, A. K., Optimization of polyhydroxybutyrate (PHB) production by Azohydromonas lata MTCC 2311 by using genetic algorithm based on artificial neural network and response surface methodology, Biocatal. Agric. Biotechnol. 1 (2012) 70. doi: https://doi.org/10.1016/j.bcab.2011.08.012

27. Singhaboot, P., Kaewkannetra, P., A higher in value biopolymer product of polyhydroxyalkanoates (PHAs) synthesized by Alacaligenes latus in batch/cyclic fed-batch fermentation processes of sugar cane juice, Ann. Microbiol. 65 (2015) 2081 doi: https://doi.org/10.1007/s13213-015-1046-9

28. Braunegg, G., Genser, K., Bona, R., Haage, G., Schellauf, F. Winkler, E., Production of PHAs from agricultural waste material, Macromol. Symp. 144 (1999) 375. doi: https://doi.org/10.1002/masy.19991440135

29. Gahlawat, G., Srivastava, A. K., Model-based nutrient feeding strategies for the increased production of polyhydroxybutyrate (PHB) by Alcaligenes latus, Appl. Biochem. Biotechnol. 183 (2017) 530. doi: https://doi.org/10.1007/s12010-017-2482-8.

30. Yu, P. H., Chua, H., Huang, A. L., Ho, K. P., Conversion of industrial food wastes by Alcaligenes latus into polyhydroxyalkanoates, Appl. Biochem. Biotechnol. 78 (1999) 445 doi: https://doi.org/10.1385/ABAB:78:1-3:445

31. Grothe, E., Chisti, Y., Poly ( $\beta$-hydroxybutyric acid) thermoplastic production by Alcaligenes latus: behavior of fedbatch cultures, Bioprocess Eng. 22 (2000) 441. doi: https://doi.org/10.1007/s004490050757

32. Sayed, E. I., Azhar, A., Abdelhady, H. M., Abdel Hafez, A. M., Khodair, T. A., Batch production of polyhydroxybutyrate (PHB) by Ralstonia eutropha and Alcaligenes latus using bioreactor different culture strategies, J. Appl. Sc. Res. 5 (2009) 556.

33. Penloglou, G., Roussos, A., Chatzidoukas, C., Kiparissides, $C$., A combined metabolic/polymerization kinetic model on the microbial production of poly (3-hydroxybutyrate), New Biotechnol. 27 (2010) 358. doi: https://doi.org/10.1016/j.nbt.2010.02.001

34. Penloglou, G., Chatzidoukas, C., Kiparissides, C., Microbial production of polyhydroxybutyrate with tailor-made properties: an integrated modelling approach and experimental validation, Biotechnol. Adv. 30 (2012) 329. doi: https://doi.org/10.1016/j.biotechadv.2011.06.021 